Article

\title{
Transcription Factors AhR/ARNT Regulate the Expression of CYP6CY3 and CYP6CY4 Switch Conferring Nicotine Adaptation
}

\author{
Yiou Pan ${ }^{1,2}$, Tianfei Peng ${ }^{2}$, Pengjun $\mathrm{Xu}^{3}{ }$, Xiaochun Zeng ${ }^{2}$, Fayi Tian ${ }^{2}$, Jiabao Song ${ }^{2}$ \\ and Qingli Shang ${ }^{1,2, * \mathbb{D}}$ \\ 1 School of Agricultural Science, Zhengzhou University, Zhengzhou 450001, China \\ 2 College of Plant Science, Jilin University, Changchun 130062, China \\ 3 Institute of Tobacco Research, Chinese Academy of Agricultural Sciences, Qingdao 266101, China \\ * Correspondence: shangqingli@163.com or shangqingli@jlu.edu.cn; Tel.: +86-431-8783-5745
}

Received: 2 August 2019; Accepted: 8 September 2019; Published: 12 September 2019

\begin{abstract}
Nicotine is one of the most toxic secondary plant metabolites in nature and it is highly toxic to herbivorous insects. The overexpression of $\mathrm{CYP6CY3}$ and its homologous isozyme CYP6CY4 in Myzus persicae nicotianae is correlated with nicotine tolerance. The expanded $(\mathrm{AC})_{\mathrm{n}}$ repeat in promoter is the cis element for $\mathrm{CYP} 6 \mathrm{CY} 3$ transcription. These repeat sequences are conserved in the CYP6CY3 gene from Aphis gossypii and the homologous P450 genes in Acyrthosiphon pisum. The potential transcriptional factors that may regulate $C Y P 6 C Y 3$ were isolated by DNA pulldown and sequenced in order to investigate the underlying transcriptional regulation mechanism of $\mathrm{CYP} 6 \mathrm{CY} 3$. These identified transcriptional factors, $A h R$ and $A R N T$, whose abundance was highly correlated with an abundance of the $C Y P 6 C Y 3$ gene, were validated. RNAi and co-transfection results further confirm that $A h R$ and $A R N T$ play a major role in the transcriptional regulation of the $C Y P 6 C Y 3$ gene. When the CYP6CY3 transcript is destabilized by AhR/ARNT RNAi, the transcription of the CYP6CY4 is dramatically up-regulated, indicating a compensatory mechanism between the CYP6CY3 and $\mathrm{CYP}_{6 \mathrm{CY}} 4$ genes. Our present study sheds light on the $\mathrm{CYP} 6 \mathrm{CY} 3$ and $\mathrm{CYP} 6 \mathrm{CY} 4$ mediated nicotine adaption of $M$. persicae nicotianae to tobacco. The current studies shed light on the molecular mechanisms that underlie the genotypic and phenotypic changes that are involved in insect host shifts and we conclude that AhR/ARNT regulate the expression of CYP6CY3 and CYP6CY4 cooperatively, conferring the nicotine adaption of M. persicae nicotianae to tobacco
\end{abstract}

Keywords: cytochrome P450; gene regulation; element; host adaptation

\section{Introduction}

Myzus persicae Sulzer (Hemiptera: Aphididae) is one of the most destructive crop pests globally. It causes damage to various host plants directly via direct feeding, plant virus transmission through feeding, and indirectly through honeydew contamination [1]. The ability of M. persicae to adapt to new host plants has led to the formation of host races. The best-documented race is associated with tobacco and it is called M. persicae nicotianae [2]. Although morphologically and genetically different from M. persicae sensu stricto (s.s.), there is clear evidence of gene flow between the two taxa [3]. Research has shown that M. persicae clones that were collected from Western Australia are successfully adapted to Lupinus angustifolius, and the improved tolerance of lupanine in their diet might confer this adaptation as compared to non-adapted clones [4].

Insects have employed cytochrome P450 monooxygenases (P450s) that promote more a rapid metabolism to defer the cost of a counter-defence against toxic plant compounds [5-11]. Members of 
the CYP3 clade have been implicated in the oxidative detoxification of furanocoumarins, alkaloids, and numerous other secondary plant metabolites and synthetic insecticides [12-15]. In tobacco-adapted M. persicae, CYP6CY3 overexpression plays a detoxifying role, protecting the insect from the plant's secondary metabolite nicotine $[16,17]$. Additionally, the constitutive overexpression of CYP6CY3 in M. persicae nicotianae as compared to M. persicae s.s, which is partly due to gene amplification, accounts for neonicotinoid resistance [16,18].

Currently, regulatory cascades in insects still largely remain a mystery. One allelochemical regulatory cascade, the xanthotoxin cascade in insects, has been well studied. In this cascade, an overlapping ecdysone response element (EcRE), antioxidant response element (ARE), xenobiotic response element to xanthotoxin (XRE-xan), and a xenobiotic response element to an aryl hydrocarbon receptor (XRE-AhR) have been functionally characterized from both the CYP6B1 and CYP6B4 promoters of Papilio polyxenes and P. glaucus, respectively [19-22]. The AhR ortholog, spineless (Ss), and the aryl hydrocarbon receptor nuclear translocator (ARNT) orthologue, tango (Tgo), both bind to XRE-AhR, which enhances the basal expression of CYP6B1 but not the magnitude of xanthotoxin and benzopyrene induction [19].

To date, there have been no reports on how transcriptional factors regulate $\mathrm{CYP6CY3}$. We chose to study the regulatory cascades of $C Y P 6 C Y 3$, which is related to nicotine tolerance $[16,18]$. In this study, we identified an element in the $\mathrm{CYP} 6 \mathrm{CY} 3$ promoter and the transcription factors that transcriptionally regulate $\mathrm{CYP} 6 \mathrm{CY} 3$. We also identified that the closely related $\mathrm{P} 450$ becomes more activated under certain circumstances. The present study sheds light on the $C Y P 6 C Y 3$ and $C Y P 6 C Y 4$ mediated nicotine adaption of M. persicae nicotianae to tobacco. In Aphis gossypii, the homologous conserved CYP6CY3 was regulated by a similar mechanism.

\section{Results}

\subsection{Knockdown of CYP6CY3 and CYP6CY4 Together Significantly Increases Nicotine Toxicity in M. Persicae Nicotianae}

The expressions of $\mathrm{CYP} 6 \mathrm{CY} 3$ and the homologous isozyme CYP6CY4 detected in previous transcriptome data (Supplementary Data S1, the transcriptome data were deposited in the National Center for Biotechnology Information/Sequence Read Archive (NCBI/SRA) database, with a SRA accession number SRX1499035 [23]) were consistent with the qPCR results reported by Peng et al. (2016a) [23]. Knocking down the expression of CYP6CY3 and CYP6CY4 together significantly increased the mortality M. persicae nicotianae (Green) (its mortality increased $30.30 \%$ in dsRNA-CYP6CY3+CYP6CY4-fed aphids) under nicotine stress, as compared with the control (Figure 1). Silencing both $\mathrm{CYP} 6 \mathrm{CY} 3$ and $\mathrm{CYP} 6 \mathrm{CY} 4$ together was more effective than just silence one P450 gene [23].
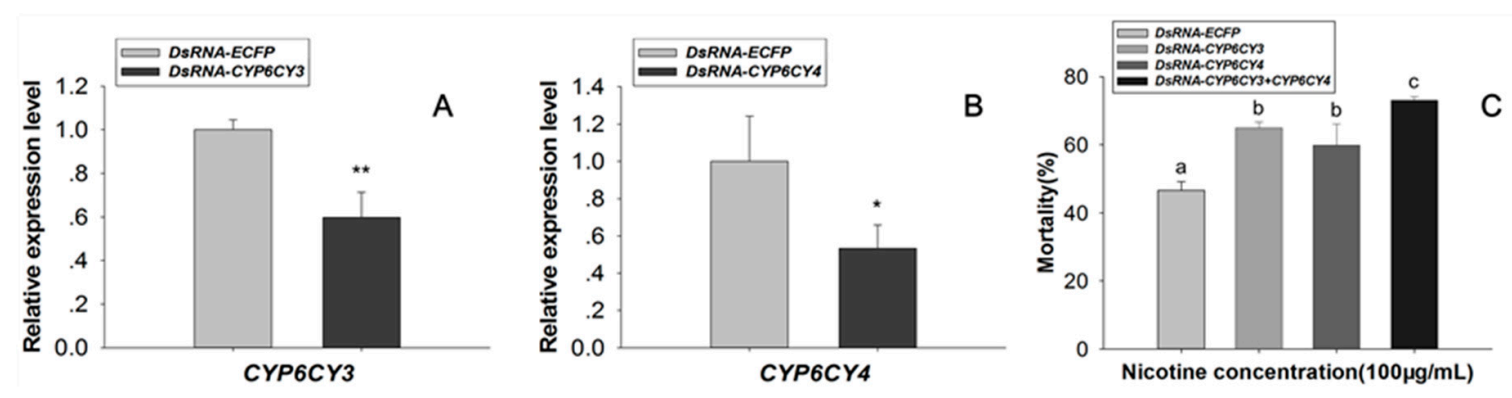

Figure 1. dsRNA-mediated suppression of $\mathrm{CYP6CY3}$ and $\mathrm{CYP6CY4}$ transcripts and its effect on nicotine toxicity in M. persicae nicotianae. (A,B) dsRNA oral-mediated knockdown efficacy $(100 \mathrm{ng} / \mu \mathrm{L}$ dsRNA-CYP6CY3 or dsRNA-CYP6CY4) after $48 \mathrm{~h}$ and the relative CYP6CY3 and CYP6CY4 expression levels in M. persicae nicotianae orally treated with dsRNA [23]. The housekeeping genes actin and para were used as internal reference genes [24]. (C) Mean mortality $\pm \mathrm{SE}(n=3)$ after feeding on a nicotine $(100 \mathrm{mg} / \mathrm{L})$ and dsRNA mixture (100 ng/ $\mu \mathrm{L}$ of dsRNA-CYP6CY3 or dsRNA-CYP6CY4 or dsRNA-CYP6CY3+CYP6CY4) 
for $48 \mathrm{~h}$ in M. persicae nicotianae. Error bars indicate $95 \%$ confidence intervals $(n=3)$. Different letters on the bars of the histogram indicate significant differences based on ANOVA, followed by Tukey's HSD multiple comparison test $(p<0.05)$. ${ }^{*}$ Significant difference by Student's $t$-test $(p<0.05) .{ }^{* *}$ Significant difference by Student's $t$-test $(p<0.01)$.

\subsection{Characterization of the Element in the CYP6CY3 Promoter Sequence}

The different lengths of the resulting PCR bands that were obtained from the M. persicae nicotianae genomic DNA digested with AfeI, EcoRV-HF, PvuII, and PmeI while using genome walking were sequenced. The sequencing results showed that all of the PCR fragments were $5^{\prime}$-flanking CYP6CY3 promoter sequences with different lengths in the $5^{\prime}$-flanking region (Genebank No. KF998221, KF998222, KF998223, KF998224, and KF998225). The longest $5^{\prime}$-flanking promoter sequence was derived from AfeI-digested genomic DNA (Figure 2, Genebank No. KF998221).

All of these sequences encoded the first $29 \mathrm{bp}$ of the CYP6CY3 coding sequence and $42 \mathrm{bp}$ of the $5^{\prime}$ UTR, but with different $(\mathrm{AC})_{\mathrm{n}}$ repeat lengths. The nucleotides are numbered relative to the transcription start site (TSS) at +1 . The upstream sequences are preceded by "-", and the downstream sequences are indicated by " + ". The sequence analysis indicated typical characteristics, such as the TATA box located at -48 -61 bp and two CAAT boxes located at the -92 -97 bp and -120 -126 bp regions. A core upstream promoter element that was located at -138 -221 bp, which was rich in $(\mathrm{AC})_{\mathrm{n}}$ repeats, was predicted by constructing matrices on the fly from TRANSFAC 4.0 sites using TRANSFAC 4.0 software in the AliBaba 2.1 database (Pairsim to know sites value is 64, the match width in bp value is 10 , the minimum number of sites is 5 , the minimum match conservation value is $75 \%$, the similarity of between the sequence and match value is $100 \%$, and the factor class level is 4). Although the putative element may or may not be a functional element in the $\mathrm{CYP} 6 \mathrm{CY} 3$ promoter, we considered its position when we made progressive and internal deletion/mutation constructs. The homology BLAST results indicated that the CYP6CY3 sequence (Genbank No. HM009309) shared $88.19 \%$ of its identity with the CYP6CY3 from Acyrthosiphon pisum at the amino acid level (NCBI Reference Sequence: NM_001366197.1). Further analysis illustrated that the CYP6CY3 promoter sequence in A. pisum also contained an $(\mathrm{AC})_{\mathrm{n}}$ repeat region, but it showed great variation in other regions (Figure S1). Two gene specific primers amplified the CYP6CY3 promoter of $A$. gossypii (New GSP1 and New GSP2) by using genome walking, and the sequencing results indicated that $A$. gossypii has a promoter with the same characterization in its $C Y P 6 C Y 3$ (Figure S2). The CYP6CY4 promoter from M. persicae that was obtained from the genome walker did not exhibit these characteristics (Figure S3).

A set of eight peach aphid CYP6CY3 promoter $5^{\prime}$ progressive deletion constructs $[\mathrm{p}(-2230 /+71)$, $\mathrm{p}(-998 /+71), \mathrm{p}(-903 /+71)$, and p(-573/+71)] (see the boundaries in Figure 2) were co-transfected into Sf9 cells with a phRL-TK control plasmid to roughly define the regions harboring a core cis element. Relative to the $\mathrm{p}(-2230 /+71)$ construct, the progressive $5^{\prime}$ deletions to -998 significantly increased the basal promoter activity, whereas the $5^{\prime}$ deletion to -903 and -578 marginally increased the promoter activity (Figure 3A). When compared with $\mathrm{p}(-998 /+71), \mathrm{p}(-903 /+71)$, and $\mathrm{p}(-573 /+71)$, the internal deletion of AC repeats [p(-998/+71)delAC, $\mathrm{p}(-903 /+71)$ delAC, and $\mathrm{p}(-573 /+71)$ delAC] completely depressed the basal promoter activity (Figure $3 \mathrm{~B}$ ). Further mutation indicated that the nearly complete removal of the $(A C)_{n}$ repeat region $[p(-998 /+71) A C m u t 2]$ abolished promoter activity, whereas the incomplete $(A C)_{n}$ repeat mutation $[p(-998 /+71) A C m u t 1]$ significantly decreased promoter activity when compared with the $p(-998 /+71)$ construct (Figure 3C,D). 


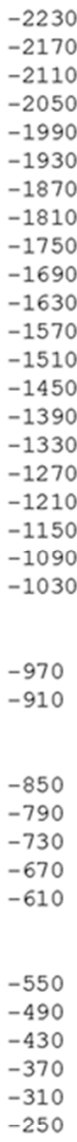

$-2230$

$-2170$

$-1990$

$-1930$

$-1750$

$-1690$

$-1570$

$-1510$

$-1450$

$-1390$

$-1270$

$-1150$

$-1090$

$-1030$

$-970$

$-910$

$-850$

$-790$

-730
-670

$-610$

$-550$

$-490$

-430
-370

-310
-250

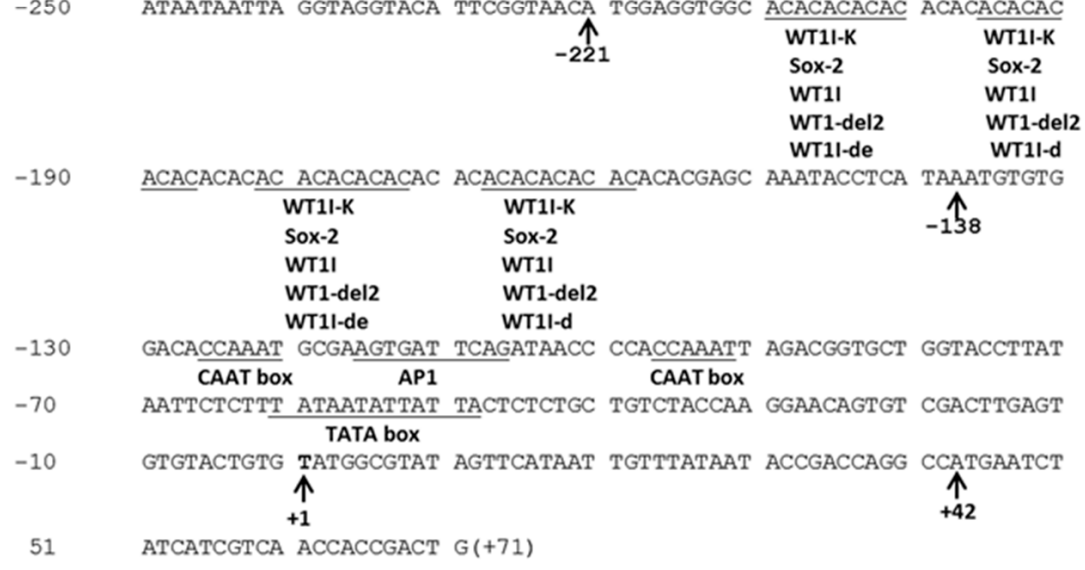

Figure 2. The promoter, $5^{\prime}$-UTR and 5'-most coding sequences of CYP6CY3 in M. persicae. The nucleotides are numbered relative to the transcription start site (TSS), indicated by +1 , with upstream sequences preceded by "-" and downstream sequences by "+". The TATA box and other putative cis elements are underlined. The start codon ATG is shown in bold. All of the left and right boundaries of the constructs made in this study are marked by an arrow and are numbered below the corresponding nucleotides.

Sequencing the DNA fragments from promoters (-278/-28) that contain AC repeat regions revealed at least five CYP6CY3 copies (with different AC repeat length: 94-, 84-, 64-, 48-, and 32-bp AC repeats) in the genome of $M$. persicae nicotianae. The transfection results indicate that the $(\mathrm{AC})_{\mathrm{n}}$ repeat expansion influenced the transcriptional activity of its promoter until it reached up to $94 \mathrm{bp}$, and the other $(\mathrm{AC})_{\mathrm{n}}$ repeats $(64-, 48-$, and 32-bp AC repeats) only confer lower basal transcription activity for their promoters (Figure 3E). The activity of $\mathrm{p}(-278 /-28$ : $94 \mathrm{AC})$ was inducible by nicotine, as compared to the control (Figure 3F).

ATTTATGACT ATAACGAGgT CGAaAgGata AAATTAATTT ATGATAAACA AAAGAGTTTG CCTACACATG AAAAATAAAA. ATGCATAATT ATTCGTAAAG GTGATATTTC ACATCAAATT CATGATAAC TAATTGGAAA CAATGAACAG AAATCCTAGA AATTTCAAAA ATAAACACAA ATAAATAAA TTCAACTACA TTTGTACTCA ACCCACCACT GGATATACAA TAATTTAATA ATCACTTTAT TAGAGTAGAA CCAATAGAAC CTACCATAAT ACCTGCGCTA GAAACAATAC ATAGAACAAA ATGATCAAAA TATTATATTA AATTACTCAA AATTATTAAT TATAATAACT CGCAACGAC GCCGTGTTGC AGATAAATAG ACAAACCAGT TAAGCAAACA AAAAACACTC AGTGCTTACA CGGAGATAAA. ATCAAATTAC TGTTTGTAAC CACATATCTG ATTAATTAGA CAATTTTTCG TAATATCTAA ATATAGAGTC TAATTACCAA TTTATAAAAT ATGTAATGCA CCGGGTTCT GATAATAATA CAATATGTTA TATGCTTATT TGTAACAGAT AAAAAAATAT ATTAGGTAA ACATACAGTT TATTTCAAAT TACAATAGG ATACCTATAT TATATATTTA GGTAGGTACT TAAGAAAAAT ATTCAAATAA TGATATTCTG AAAGCAATAC AATTTATAAT AATATGTTC TAATATAGTA ATATATTATT ATGCTTTACT ACTTAGTTTT TAAATTATGC TGATTGCATT GTATTTTAGA AGTTATTCAA AAAATAAAAA ATTTCAAAAA AGATAGTGTA TTACTTTG AGATGATAAC AGCGCACTGT TTGTTTTCTC TCTATGAGCC ACGCGCAACA ATAGCTTTAG TATTGGATTG $-988$

TTGAACTA TTTTGAAATT TAAATTTTCA AACGTTATCT GTATTCTTAA GTTGCCTTTA GGTATT ATAATTTTTA TGCGAGTAAT GAATTTATGT AAAATGTTAC AATTTAAAAA

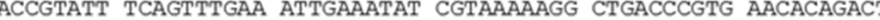

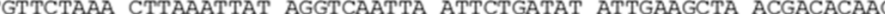
GAAACTTTGT AAATATTACT ATCGTTATTT TAGTTTTATT ATGTACCCAT TCAAAATAAG ATTTAGACCA TCGTGGTTTA ATTTAATTTT ACTGTACGTA ACTTCAATAC AATGATTGGA

TTTTAATTTA TAAAATAATA ACTATGCGAC ATAATATCAA TGTATAATAC ACAGTAATAC GTGTATAat TTAAAAACCA AGTAGGAATT AAAgTATAAT ATACACCCGT GATTTAGAAA CTTGAACTAG AAATAAAATC AAATTCAAAC TTTAATAATA AATATAGTTC AACTTATTCA AAGTACTGTG CACCCAGCAC CATTATACTA GGGACACACA TTATAATCTC ATACCCCCGG GAAAATACGC AGAAAAATAT CGATAGAATT TTATACTCTC GTCTGAACGT CTAACACTTA GAAAATACGC AGAAAAATAT CGATAGAATT TIATACTCTC GTCTGAACGT CTAACACTMA WT1-del2 $-57_{3}$ 


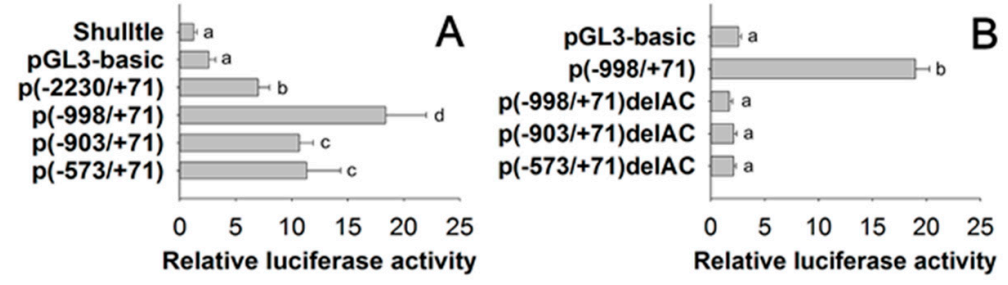
Mut1: ATGGTGGAGGTAGACTCACTCTCACAGAGTGACACTCTGAGACTCAGAGTCTCTCTGTGAGACTCTCGAGGTTATACGTCATAA
Mut2: ATGGAAGTCGCACATACGCATACCCATACTCATACGCATACCCATACTCATACGCATACCCATACTCGCGCGAACACGTCATAA Wildtype: (-221) ATGGAGGTGGCACACACACACACACACACACACACACACACACACACACACACACACACACACACACGAGCAAATACCTCATAA(-138)

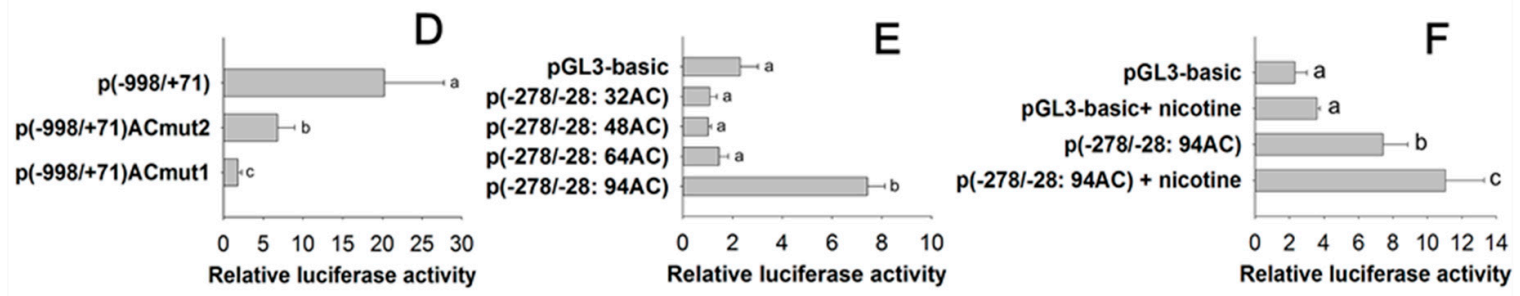

Figure 3. Mapping of core cis elements in the CYP6CY3 promoter region by $5^{\prime}$ progressive deletions (A), internal deletions (B) and mutations $(\mathbf{C}, \mathbf{D})$, and the effect of $(A C)_{n}$ repeat length on promoter activity (E) and its nicotine-inducible activity (F).The name of each CYP6CY3 promoter-pGL3 construct contains a " $\mathrm{P}$ " and a pair of parentheses with two numerals separated by a dash to specify the $5^{\prime}$ and $3^{\prime}$ positions of the corresponding promoter fragment. For internal deletion or substitution mutation constructs, the name of the deleted or mutated sequence and a "-del" or "-mut" are added after the parentheses. The deleted region was $\sim-221-138$ as shown in Figure S2. The mutated nucleotides in the $(\mathrm{AC})_{\mathrm{n}}$ repeats are bold and shown in italics. The final concentration of nicotine for induction was $24.7 \mu \mathrm{M} / \mathrm{L}$. Different letters on the bars of the histogram indicate significant differences based on an ANOVA, followed by Tukey's HSD multiple comparison test $(p<0.05)$.

\subsection{Identification of Core Cis Element Binding Proteins}

The proteins isolated by DNA pulldown were analysed via capillary high-performance liquid chromatography-mass spectral analysis (CE/HPLC-MS; Aptbiotech Co., Ltd., Shanghai, China) to identify the cis element that binds the nuclear proteins. A total of 955 proteins were positively identified (Supplementary Data S2). These identified proteins included many non-target proteins and transcription related proteins, such as DNA-directed RNA polymerase, RNA recognition protein, pre-mRNA processing factor, putative RNA polymerase II elongator, and DNA topoisomerase. The transcription factor proteins were also isolated, including the aryl hydrocarbon receptor (AhR), the putative $\mathrm{c} 2 \mathrm{~h} 2$-type $\mathrm{zn}$-finger protein $(\mathrm{CncC})$, and the cyclic AMP-dependent transcription factor (Camp).

The $A h R$ and $A R N T$ sequence were obtained from the transcriptome of the M. persicae (The National Center for Biotechnology Information/Sequence Read Archive (NCBI/SRA) database, SRA experiment accession number: SRX1499035) [23]. The alignment of the AhR and ARNT of M. persicae with the paralogs genes of Drosophila indicated that they share the same basic highly conserved domain, helix-loop-helix (bHLH), and the period (Per)-ARNT- single-minded (Sim) (PER-ARNT-SIM, PAS) (Figures 4 and 5). The bHLH domain participates in the binding of the transcription factors to the DNA and it promotes protein-protein interaction, and the PAS domain supports specific secondary interactions with other PAS domains of AHR and ARNT [25,26]. The glutamine-rich (Q-rich) domain is located in the C-terminal region, which is involved in the recruitment and activation of co-activators [27]. 


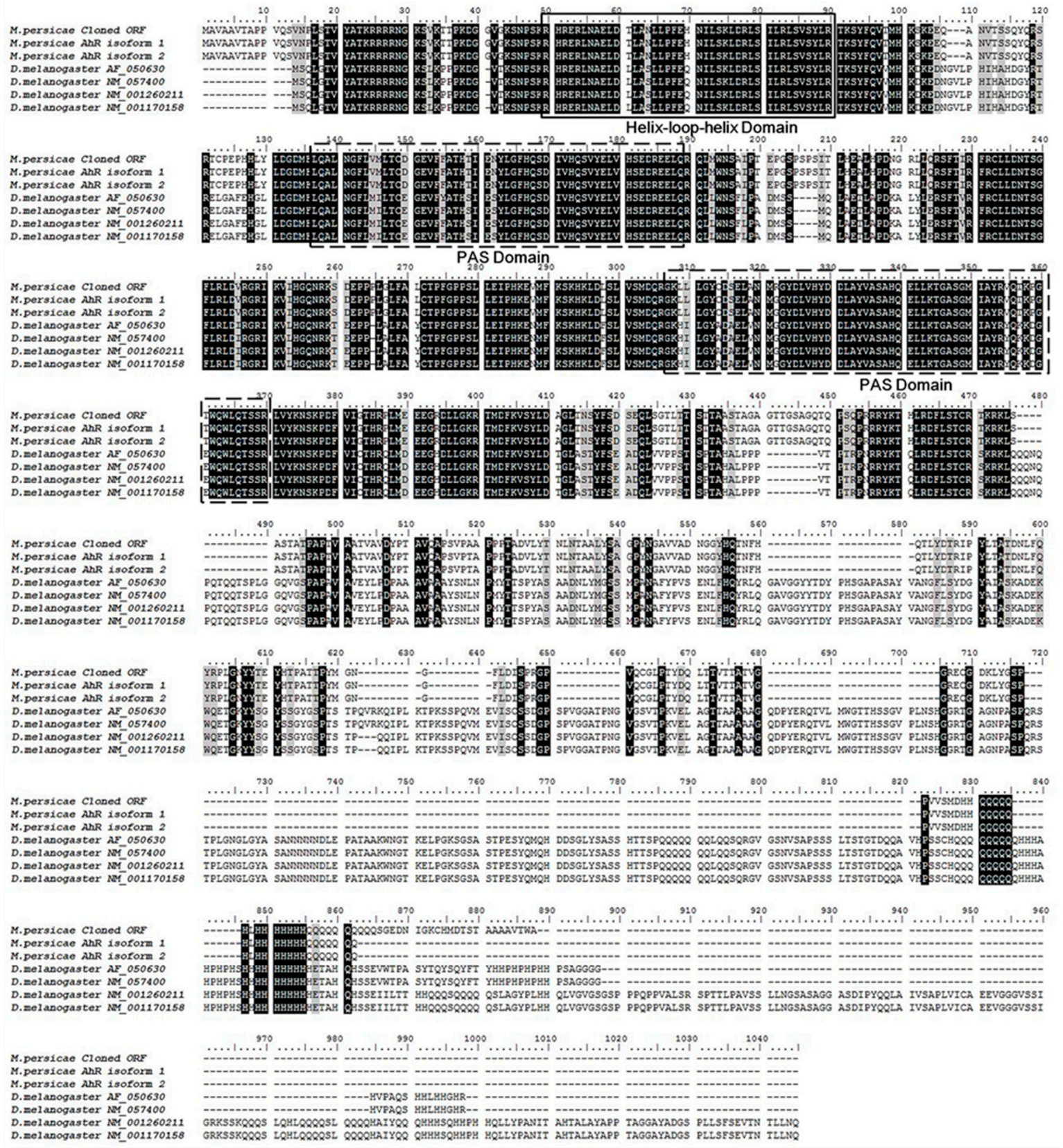

Figure 4. Alignment of the amino acid sequences of $A h R$ of insect species. The amino acid sequence of AhR of M. persicae shares a high level of homology with that of D. melanogaster. The conserved domains common to AhRs are boxed, including the basic helix-loop-helix (bHLH) and PER-ARNT-SIM (PAS) specific to $A h R$ members. The bHLH region is involved in the binding of the transcription factor to DNA and facilitates protein-protein interactions. The PAS domains support specific secondary interactions with other PAS domain containing proteins, as is the case with AhR and ARNT. The glutamine-rich (Q-rich) domain is located in the C-terminal region of the protein and it is involved in co-activator recruitment and transactivation The $A h R$ sequences of $D$. melanogaster were downloaded from Gene Bank with the accession number: AF050630, NM057400, NM001260211 and NM001170158. The AhR sequences of M. persicae were got from the transcriptome with the unigene number of c18023_g2_i1 and c18023_g2_i2 for $A h R$ isofrom 1 and $A h R$ isofrom 2, respectively (The clean reads obtained in this study were submitted to the NCBI/SRA database, SRA experiment accession number: SRX1499035). 

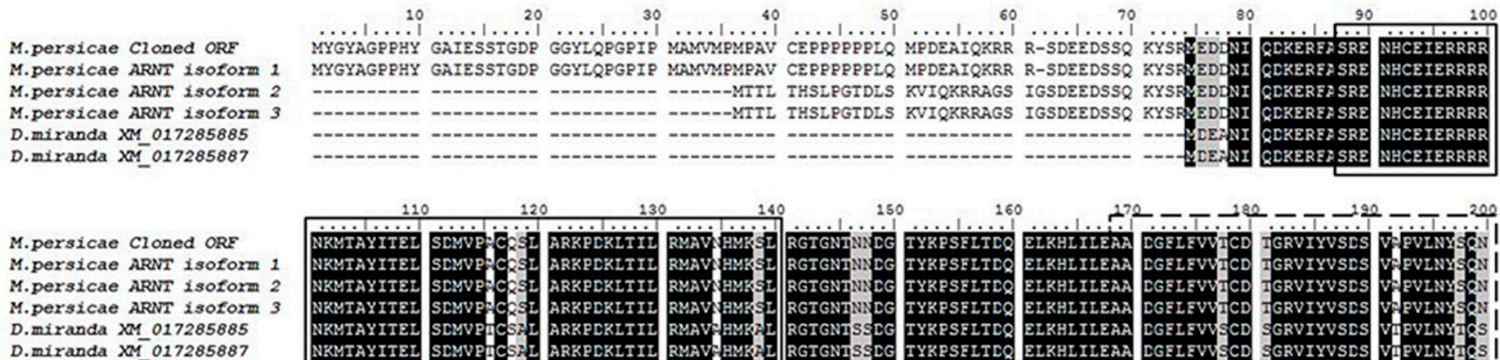

M.persicae Cloned ORF ARNT isotorm M.persicae ARNT isoform D.miranda XM ${ }^{2}-017285885$

M.persicae Cloned ORF M.persicae ARNT isoform 1 M.persicae ARNT isoform 2 M.persicae ARWr 1soform D.miranda Xk! 017285805
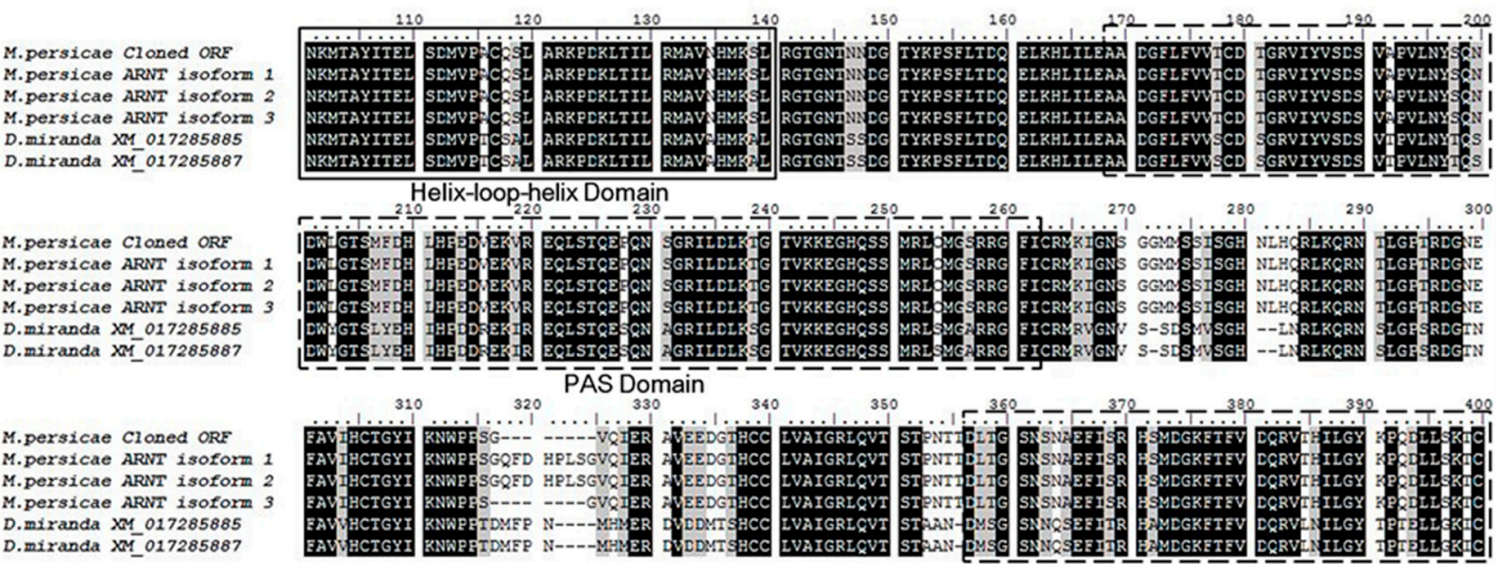
D.miranda $\mathrm{XM}^{-} 01728588$

M.persicae Cloned ORF M.persicae ARNT isoform 1 M.persicae ARNT isoform 2 M.persicae ARNr 1soform D.miranda XM-017285885
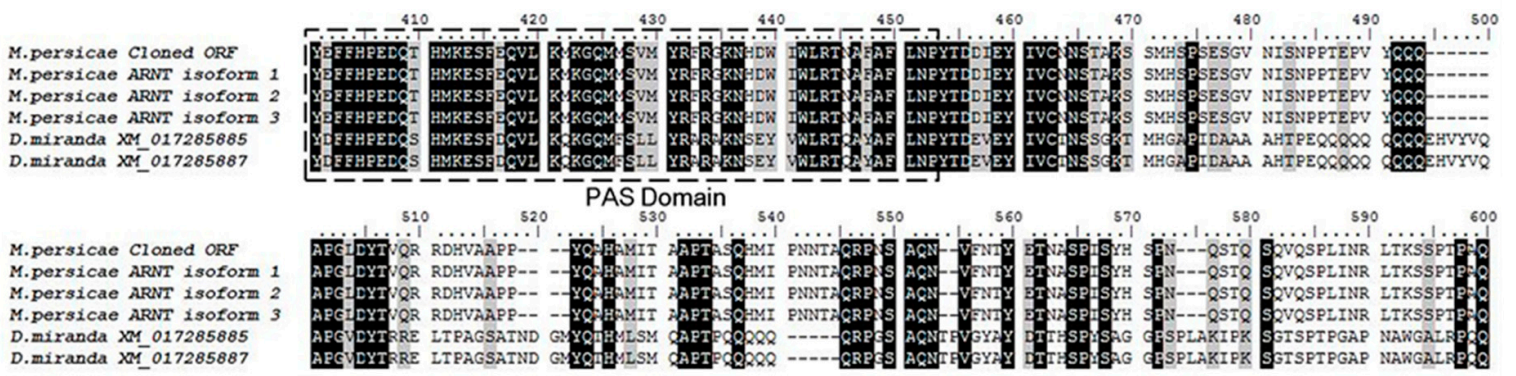

M.persicae Cloned ORF M.persicae ARNT isoform 1 M.persicae ARNT isoform 2 M.persicae ARNT isoform 3 D.miranda XY 017285885 D.miranda $\mathrm{XM}_{-} 017285887$

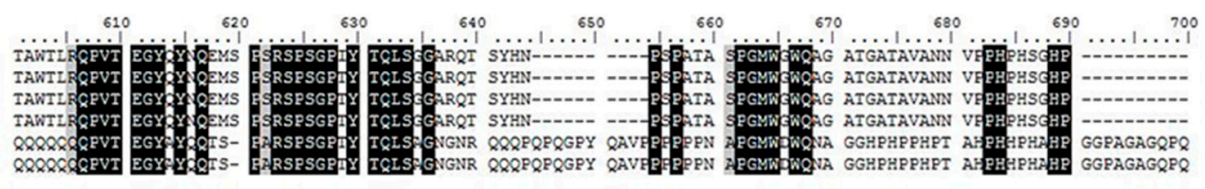

M.persicae Cloned ORF

M.persicae ARNT isoform 1

M.persicae ARNT 1soform 2 D. miranda XM 017285885 D. miranda $x M^{-} 017285887$

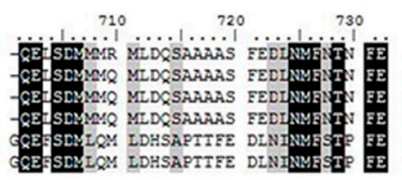

Figure 5. Alignment of the amino acid sequences of $A R N T$ of insect species. The amino acid sequence of ARNT of M. persicae shares a high level of homology with that of $D$. miranda. The conserved basic helix-loop-helix (bHLH) and PER-ARNT-SIM (PAS) domains specific to ARNT members are boxed. The ARNTs Gene Bank number of D. miranda were XM017285885 and XM017285887. The corresponding unigene numbers of $A R N T$ isofrom 1, ARNT isofrom 2 and ARNT isofrom 3 of M. persicae were c16053_g1_i1, c16053_g1_i2 and c16053_g1_i3, respectively (SRA experiment accession number: SRX1499035) [23].

\subsection{Regulation Effect of $A h R$ and $A R N T$ on $C Y P 6 C Y 3$}

The expression levels of $A h R, A R N T$, and Camp (see sequences in Supplementary Data S3) in M. persicae nicotianae (Green) were significantly higher than those in M. persicae sensu stricto (Green) and M. persicae sensu stricto (Red) (Figure 6A,B,E). Orally delivered dsRNA mediated the RNAi knockdown of $A h R, A R N T$, and Hsp90, and dramatically reduced CYP6CY3 transcription (the expression of CYP6CY3 declined $60.97 \%, 31.20 \%, 64.76 \%$, and $72.76 \%$ in the RNAi of $A h R, A R N T, A h R$, plus ARNT, and Hsp90 treated aphids, respectively). The knockdown of $\mathrm{CncC}$ and Camp suppressed CYP6CY3 expression (Figure 6F-I), whereas CncC overexpression did not increase CYP6CY3 promoter activity (data not shown). Co-transfection of $A h R$ and ARNT significantly elevated CYP6CY3 promoter activity 1.92- 
and 4.18-fold, respectively (Figure 6J). The repression of $A h R$ and $A R N T$ expression also significantly down-regulated CYP6CY3 expression in A. gossypii (Figure S4) [28].
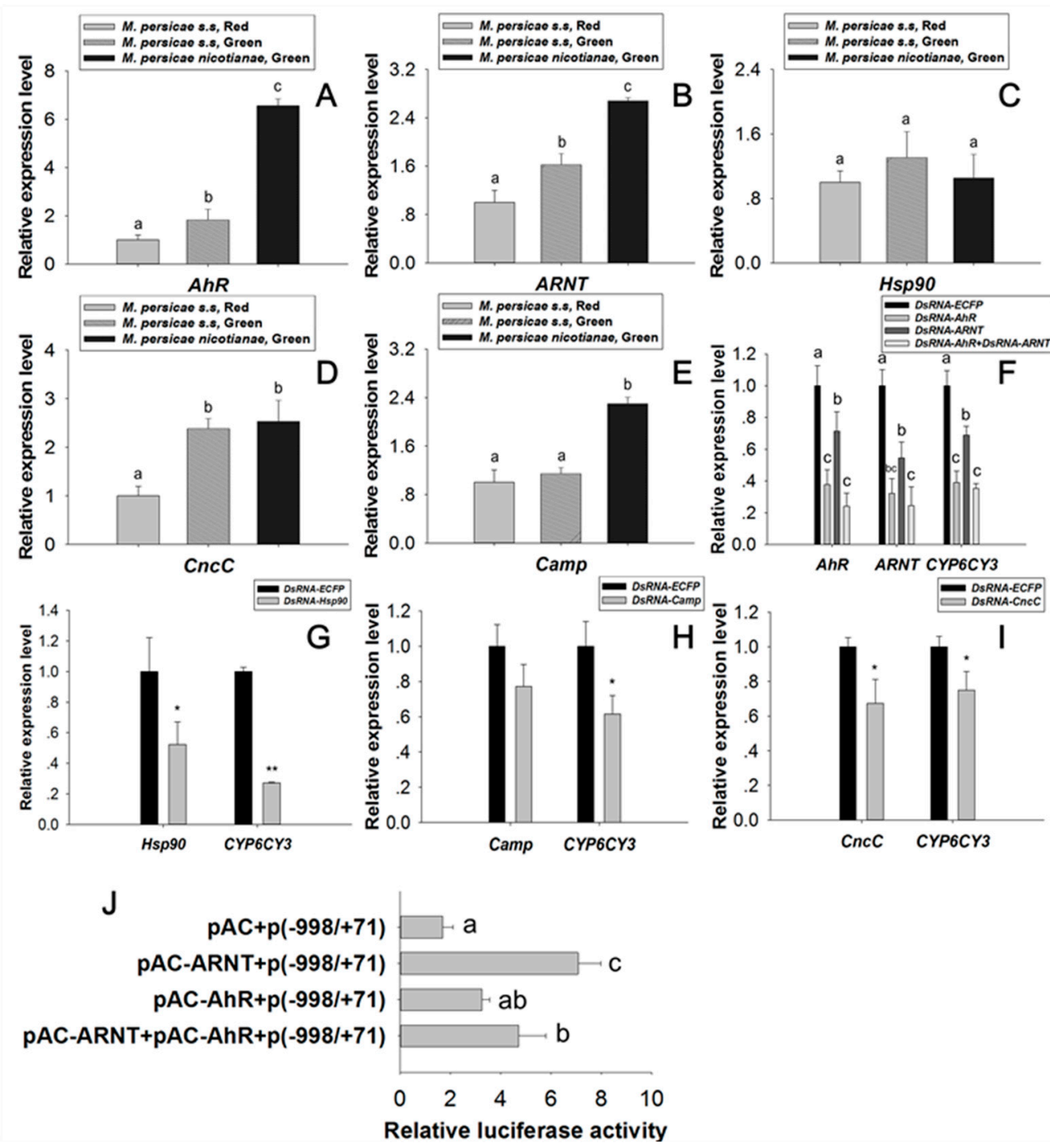

Figure 6. Functional characterization of $C Y P 6 C Y 3$ regulation by $A h R-A R N T$. (A-E) The relative $A h R$, $A R N T, H s p 90, C n c C$, and Camp transcript levels in the three M. persicae races. (F-I) Orally mediated dsRNA knockdown efficacy (100 ng/ $\mu \mathrm{L}$ of corresponding dsRNA) after $48 \mathrm{~h}$ and its effects on CYP6CY3 transcriptional regulation. (J) The effect of $A h R$ and ARNT overexpression on CYP6CY3 promoter activity. The housekeeping genes actin and para were used as internal reference genes [24]. Different letters on the bars of the histogram indicate significant differences based on ANOVA followed by Tukey's HSD multiple comparison test $(p<0.05)$. ${ }^{*}$ Significant difference by Student's $t$-test $(p<0.05)$. ** Significant difference by Student's $t$-test $(p<0.01)$.

\subsection{Transcription Factor Modulation Impacts CYP6CY4 Expression}

A compensatory mechanism may exist between the $\mathrm{CYP} 6 \mathrm{CY} 3$ gene and its homologous $\mathrm{CYP6CY4}$ gene [23]. For example, CYP6CY4 knockdown significantly increased the expression of CYP6CY3 (2.22-fold) in treated aphids (Figure 7A). Similarly, the expression of CYP6CY4 dramatically increased (1.66-fold) in the CYP6CY3-depleted aphids (Figure 7B) [23]. The orally delivered transcription factor dsRNA also had opposite effects on the transcription of CYP6CY4 to those of CYP6CY3. The RNAi knockdown of $A h R$ and $A R N T$ dramatically reduced $C Y P 6 C Y 3$ levels (Figure 6F), but significantly 
increased CYP6CY4 expression 4.93- and 4.69-fold in the dsRNA-AhR and dsRNA-ARNT fed aphid, respectively (Figure 7C).
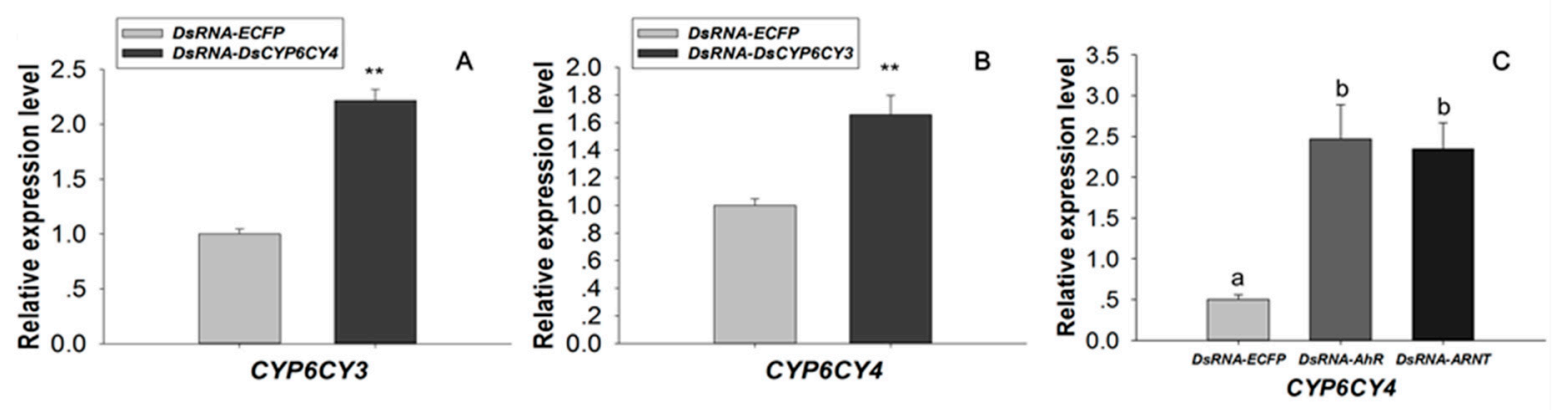

Figure 7. The effects of $A h R$ and ARNT modulation on CYP6CY4 expression in M. persicae nicotianae. (A,B) The relative $C Y P 6 C Y 3$ and $C Y P 6 C Y 4$ expression levels in M. persicae nicotianae orally treated with dsRNA (100 ng/ $\mu \mathrm{L}$ dsRNA-CYP6CY4 or dsRNA-CYP6CY3) after 48 h [23]. (C) Orally mediated dsRNA knockdown of $A h R$ or $A R N T$ (100 ng of $A h R$ or ARNT dsRNA) impacts CYP6CY4 transcriptional level. The housekeeping genes actin and para were used as internal reference genes [24]. Different letters on the bars of the histogram indicate significant differences based on ANOVA followed by Tukey's HSD multiple comparison test $(p<0.05) .{ }^{* *}$ Significant difference by Student's $t$-test $(p<0.01)$.

\section{Discussion}

Herbivorous insects have evolved a complex of regulatory machinery and they have experienced substantial increases in P450 metabolic activity to address exposure to allelochemicals [8-11,21]. This response is essential for insects to counter the effects of toxins that are generated by host plants. Larval tolerance to gossypol in the cotton bollworm was reduced following CYP6AE14 silencing with plant-mediated RNAi $[29,30]$. The overexpression of $C Y P 6 C Y 3$ in M. persicae nicotianae as compared to $M$. persicae s.s is partly due to gene amplification, which accounts for nicotine and neonicotinoid resistance [16,18]. The RNAi of CYP6CY3 and CYP6CY4 together is more effective for increasing nicotine toxicity to M. persicae nicotianae than RNAi of a single P450 gene (Figure 1). The regulatory cascades that are induced by exposure to plant toxins in insects remain largely unknown.

The motifs in the promoter region (cis-elements) directly upstream of the genes that are responsible for the binding of transcription factors, are likely candidate regions for controlling the transcription of tolerance-associated genes [31,32]. However, the identification of cis-regulatory elements poses a notable challenge. A cis-acting element, designated as the xenobiotic response element to the flavone (XRE-Fla), was characterized in Helicoverpa zea as a mediating xanthotoxin and the flavone-inducible expression of CYP321A1 [33,34]. The CncC-Maf binding site that is responsive for xenobiotic-induced transcription in the promoter regions of the CYP6BQ and CYP6A2 genes was identified in Tribolium castaneum and Drosophila, respectively $[35,36]$. A xenobiotic response element to the aryl hydrocarbon receptor (XRE-AhR) has been functionally characterized for both the CYP6B1 and CYP6B4 promoters in Papilio polyxenes and P. glaucus $[19,22]$. No such conserved element has been identified in the CYP6CY3 promoter. Instead, tandem $(\mathrm{AC})_{\mathrm{n}}$ repeats were observed in the $\mathrm{CYP} 6 \mathrm{CY} 3$ promoter in $M$. persicae (Figure 2,). These conserved repeats were also found in the CYPCY3 promoter in A. pisum, which shares high homology with the M. persicae CYP6CY3 gene (Figure S1). Research showed that tandem repeats, combined with a variation of genetic and epigenetic characteristics, contribute to the evolutionary ability of organisms [37]. Repeat sequences are responsive elements in promoters that regulate gene expression by affecting local chromatin structure. [38]. Functional characterization indicated that the $(\mathrm{AC})_{\mathrm{n}}$ repeat is the responsive element for $\mathrm{CYP} 6 \mathrm{CY} 3$ transcription (Figure $3 \mathrm{~A}-\mathrm{D}$ ). In humans, the $(\mathrm{AC})_{\mathrm{n}}$ repeat is a major contributor to transcriptional regulation, and hence to phenotypic variation [39]. For example, variation in the $(A C)_{n}$ repeat number alone influenced the rates of transcription in the metalloproteinase-9 gene $[40,41]$. The $(\mathrm{AC})_{\mathrm{n}}$ repeats in the CYP6CY3 promoters of CYP6CY3 copies that were derived from M. persicae nicotianae were of significantly varied lengths. The $(\mathrm{AC})_{\mathrm{n}}$ repeat 
expansion influenced the transcriptional activity of its promoter until it reached up to $94 \mathrm{bp}$ and was nicotine inducible (Figure 3E,F). Thus, (AC) n repeat length (up to 94-bp) increased CYP6CY3 promoter activity, which might subsequently elevate the nicotine tolerance ability of aphids.

Potential transcription factors, such as AhR, were identified by DNA pulldown combined with mass spectrometry and bioinformatics analysis (Supplementary Data S2). AhR belongs to the bHLH/PAS protein family. The bHLH domain participates in the binding of transcription factors to DNA and it promotes protein-protein interaction, and the PAS domains function as secondary dimerization domains, promoting interactions with another bHLH/PAS protein (i.e., ARNT) [42]. AhR is a ligand-activated transcription factor that mediates many of the responses to toxic chemicals. In the absence of the ligand, AhR is present in a cytosolic complex with heat shock protein 90 (Hsp90) [43], maintaining AhR in a quiescent (non-DNA binding) state. Upon binding with the ligand, the AhR complex translocates into the nucleus, and then dissociates from the molecular chaperone heat shock protein 90 (Hsp90) complex to form a heterodimer with ARNT. The alignment of AhR and ARNT of the M. persicae nicotianae with paralogs genes of Drosophila indicated that they share the highly conserved domain of bHLH and PAS (Figures 4 and 5), which demonstrates that the AhR and ARNT of M. persicae nicotianae might have a similar function to Drosophila. The AhR/ARNT heterodimer binds the xenobiotic responsive elements (XRE) in the promoter, leading to the transcription of genes that encode xenobiotic metabolism enzymes, such as cytochrome P450 genes, which in mammals include CYP1A1, CYP1A2, and CYP1B1 [44-51]. In our study, RNAi of $A h R$ and ARNT dramatically down-regulated CYP6CY3 expression in M. persicae nicotianae (Figure 6), and the co-transfection results further confirmed that the transcription of $C Y P 6 C Y 3$ is regulated by AhR-ARNT pathway in M. persicae (Figure 6). This process generates significantly elevated the $A h R$ and $A R N T$ expression in M. persicae nicotianae as compared to M. persicae s.s. and accounts for its tolerance to nicotine (Figure 6). A different promoter expresses the CYP6CY3 homologous P450-CYP6CY4 (Figure S3); its expression level dramatically increased when the $C Y P 6 C Y 3$ transcripts were knocked down, and the RNAi of AhR and ARNT had opposite effects on the transcription of $C Y P 6 C Y 4$ to those of $C Y P 6 C Y 3$ (Figure 7). However, $C Y P 6 C Y 3$ expression was significantly elevated when the $\mathrm{CYP6CY4}$ transcripts were repressed (Figure 7). This indicates that the CYP6CY3 and $\mathrm{CYP6CY} 4$ genes cooperatively cope with nicotine stress. These results, combined with the effects on nicotine toxicology (Figure 1), illustrate that $C Y P 6 C Y 4$ has a similar role in the response to nicotine tolerance and that the ability to shift the expression of specific genes might have driven the evolution of $M$. persicae nicotianae's tolerance to nicotine stress.

The present study indicates that $C Y P 6 C Y 3$ are transcriptionally regulated by AhR and ARNT, and the significant up-regulation of $A h R$ and $A R N T$ expression further strengthen the transcription level of $C Y P 6 C Y 3$ in M. persicae nicotianae. This process, in combination with CYP6CY3 and CYP6CY4 switchover, conferred an adaptive evolution to nicotine.

\section{Materials and Methods}

\subsection{Insects and Cell Culture}

Three M. persicae clones were established from a population originally collected in 2008 from a field in Jilin province, China. The M. persicae sensu stricto population (green/red morph) was sampled and reared on Chinese cabbage (Brassica rapa chinensis). M. persicae nicotianae (green morph) was collected and then reared on tobacco (Nicotiana tabacum L.) at $21-23^{\circ} \mathrm{C}$ with a $16: 8 \mathrm{~h}$ light:dark photoperiod.

Sf9 cells were routinely cultured in a SF-900 II serum-free medium (Invitrogen, Carlsbad, CA, USA) supplemented with 10\% heat-inactivated fetal bovine serum (FBS, Hyclone-QB Perbio, Logan, $\mathrm{UT}), 50 \mathrm{U} / \mathrm{mL}$ penicillin, $50 \mu \mathrm{g} / \mathrm{mL}$ streptomycin, and $12 \mu \mathrm{g} / \mathrm{mL}$ gentamycin (Invitrogen) at $28^{\circ} \mathrm{C}$.

\subsection{Quantitative RT-PCR and Data Analysis}

Total RNA was extracted from the apterous adult aphids with TRIzol (Invitrogen, Carlsbad, CA, USA), according to the manufacturer's instructions and treated with RNase-free DNase I (TaKaRa, 
Kyoto, Japan). cDNA was synthesized from the total RNA while using a PrimeScrip ${ }^{\mathrm{TM}}$ First-Strand cDNA Synthesis kit (TaKaRa) with oligo $(\mathrm{dT})_{18}$ as the primer. The housekeeping genes actin and para, which encode a voltage-gated sodium channel, were used as internal reference genes for M. persicae nicotianae [24].

Quantitative real-time PCR was performed on an ABI 7500 (Applied Biosystems) while using SYBR $^{\circledR}$ Premix Ex Taq ${ }^{\text {TM }}$ II (Tli RNaseH Plus; TaKaRa). Gene-specific primers for real-time PCR (Table S1) were synthesized by Sangon Biotech Co., Ltd. (Shanghai, China). The thermal cycling protocol included an initial denaturation at $95^{\circ} \mathrm{C}$ for $30 \mathrm{~s}$, followed by 40 cycles of $95^{\circ} \mathrm{C}$ for $5 \mathrm{~s}$ and $60{ }^{\circ} \mathrm{C}$ for $34 \mathrm{~s}$. The fluorescence signal was measured at the end of each extension step at $60{ }^{\circ} \mathrm{C}$. After the amplification, a dissociation step cycle at $95^{\circ} \mathrm{C}$ for $15 \mathrm{~s}, 60^{\circ} \mathrm{C}$ for $1 \mathrm{~min}$., and $95^{\circ} \mathrm{C}$ for $15 \mathrm{~s}$ was performed to confirm that only the specific products were amplified. Relative gene expression was calculated with the $2^{-\Delta \Delta C T}$ method [52]. The experiment was independently performed three times for each strain. Significant differences were analysed using the GraphPad InStat3 statistical software (GraphPad Software, 2000).

\subsection{Cloning of CYP6CY3 5' Flanking Sequences and Sequence Analyses}

Genomic DNA from M. persicae nicotianae and A. gossypii was isolated from apterous adult aphids using the DNAzol kit (Takara). The GenomeWalker ${ }^{\mathrm{TM}}$ Universal kit (Clontech, Palo Alto, CA, USA) was used to obtain the $5^{\prime}$-flanking promoter sequence of $C Y P 6 C Y 3$. First, $M$. persicae nicotianae genomic DNA was digested with AfeI, EcoRV-HF, PvuII, SmaI, SnaBI, PmeI and StuI restriction enzymes. The genomic DNA of A. gossypii was digested by AfeI, PvuII, EcoRV-HF, SmaI, PsiI, PmeI, StuI and BstZ17I. Then, the digested DNA fragments were ligated into the genome walking adapters according to the manual's instructions (see adapters and primers in Table S1). The resulting DNA fragments were used as templates for amplifying the $\mathrm{C} Y \mathrm{P} 6 \mathrm{C} Y 3$ promoter sequence using two forward primers (AP1 and AP2) complementary to the adapter sequences, as well as CYP6CY3/CYP6CY4 specific reverse primers (GSP1 and GSP2; 6CY4-GSP1 and 6CY4-GSP2) for $M$. persicae and two specific reverse primers (newGSP1 and newGSP2) for A. gossypii. The PCR protocol was performed according to the kit's instructions. The bands were gel eluted using the TIANgel Midi Purification Kit (Tiangen) and were directly cloned into the pGEM-Teasy vector (Promega). The positive clones were selected for sequencing.

Searches for homologous sequences were performed while using BLASTN against the NCBI database (http://www.ncbi.nlm.nih.gov/). Promoter predictions for sequences with a score cut-off of 0.80 were identified with the BDGP database (http://www.fruitfly.org/seq_tools/promoter.html). Transcription factor binding sites were assessed by constructing matrices on the fly from TRANSFAC 4.0 sites while using TRANSFAC 4.0 software and the AliBaba 2.1 database (http://www.gene-regulation. $\mathrm{com} /$ pub/programs/alibaba2/index.html), with specific parameters (Pairsim to know sites value is 64, the match width in bp value is 10 , the minimum number of sites is 5 , the minimum match conservation value is $75 \%$, the similarity of sequence to match value is $100 \%$, and the factor class level is 4 ).

\subsection{Construction of CYP6CY3 Promoter-pGL3 Constructs}

PCR was employed to generate the following three types of $C Y P 6 C Y 3$ promoter reporter gene constructs: progressive $5^{\prime}$ deletion-pGL3 constructs, internal deletion-pGL3 constructs, and multiple base pair substitution-pGL3 constructs. The common template for progressive $5^{\prime}$ and $3^{\prime}$ deletion-pGL3 constructs was $\mathrm{p}(-2230 /+71)$, which contained the $2301 \mathrm{bp} 5^{\prime}$-flanking sequence from CYP6CY3 that was obtained via genome walking. The obtained sequence was cloned into the pGL3 basic vector containing the first $29 \mathrm{bp}$ of the CYP6CY3 coding sequence, $42 \mathrm{bp}$ of the $5^{\prime} \mathrm{UTR}$, and $2230 \mathrm{bp}$ of the promoter sequence. Throughout this paper, we report the nucleotide position in the proximal promoter relative to the transcriptional start site $(+1)$ with upstream positions being preceded by "-" and downstream positions preceded by " + ". 
Progressive $5^{\prime}$ deletion fragments for $5^{\prime}$ deletion constructs, including $\mathrm{p}(-2230 /+71), \mathrm{p}(-998 /+71)$, $\mathrm{p}(-903 /+71)$, and $\mathrm{p}(-573 /+71)$, were amplified while using the universal reverse primer 6CY3-XhoI and one of the forward primers 6CY3-2230-MluI, 6CY3-998-MluI, 6CY3-903-MluI, or 6CY3-573-MluI (see Table S1 for sequences). PCR was performed in a $50 \mu \mathrm{L}$ mixture containing $10 \mu \mathrm{L} 5 \times$ PCR buffer, $1 \mu \mathrm{L} 10 \mathrm{mM}$ dNTP, 20 pmol primer pairs, $0.2 \mu \mathrm{g}$ p(-2230/+71) template, and $2 \mathrm{U}$ of LongAmpTaq DNA polymerase (New England Biolabs, NEB). The thermal cycling protocol was as follows: $94{ }^{\circ} \mathrm{C}$ for 5 min.; 25 cycles of $94^{\circ} \mathrm{C}$ for $30 \mathrm{~s}, 55^{\circ} \mathrm{C}$ for $30 \mathrm{~s}, 65^{\circ} \mathrm{C}$ for 2 min.; and, a final extension at $65^{\circ} \mathrm{C}$ for $10 \mathrm{~min}$. The resulting band from each deletion fragment was gel eluted while using the TIANgel Midi Purification Kit (Tiangen, Beijing, China) and it was cloned into the XhoI and MluI sites of the pGL3-Basic vector (Promega).

Three internal deletion constructs (deleting the sequence from -221 to -138), including $\mathrm{p}(-998 /+71)$ delAC, $\mathrm{p}(-903 /+71)$ delAC and $\mathrm{p}(-573 /+71)$ delAC, were generated using $\mathrm{p}(-998 /+71)$, $\mathrm{p}(-903 /+71)$, or $\mathrm{p}(-573 /+71)$ as the template, respectively, and the ACdelF and ACdelR primer pairs. Two multiple base pair substitution mutation-pGL3 constructs, $\mathrm{p}(-998 /+71) A C$ mut1 and $\mathrm{p}(-998 /+71)$ ACmut2, were made while using $\mathrm{p}(-998 /+71)$ as the template and two pairs of primers (MutF1 and Mut R1, MutF2 and MutR2; Table S1). PCR was performed in a $50 \mu \mathrm{L}$ mixture containing $10 \mu \mathrm{L} 5 \times$ PCR buffer, $1 \mu \mathrm{L} 10 \mathrm{mM}$ dNTP, 20 pmol primer pairs, $0.2 \mu \mathrm{g}$ template, and $2 \mathrm{U}$ LongAmpTaq DNA polymerase (NEB). The thermal cycling protocol was as follows: $94{ }^{\circ} \mathrm{C}$ for $5 \mathrm{~min}$.; 25 cycles of $94{ }^{\circ} \mathrm{C}$ for $30 \mathrm{~s}, 55^{\circ} \mathrm{C}$ for $30 \mathrm{~s}, 65^{\circ} \mathrm{C}$ for $6 \mathrm{~min}$.; and, a final extension at $65^{\circ} \mathrm{C}$ for $10 \mathrm{~min}$. The resulting PCR band was purified with a TIANgel Midi Purification Kit (Tiangen, Beijing, China), end-blunted for $15 \mathrm{~min}$. at $12{ }^{\circ} \mathrm{C}$ with T4 DNA polymerase (NEB), $5^{\prime}$-phosphorylated for $20 \mathrm{~min}$. at $37^{\circ} \mathrm{C}$ with T4 polynucleotide kinase ( 3 'phosphatase minus; NEB), and finally self-ligated overnight at $16^{\circ} \mathrm{C}$ with T4 DNA ligase (NEB) to generate the constructs.

Based on the results, the DNA fragments from the promoters (-278/-28) containing the $(A C)_{n}$ repeat region (shown in Figure 2) were amplified from single apterous adult aphid of M. persicae nicotianae and M. persicae s.s while using the primer pair Pulldown-F and Pulldown-R (Table S1). These DNA fragments containing 94-, 64-, 48-, or 32-bp AC repeats were cloned into the pGL3 basic vector while using MluI and XhoI restriction sites to construct $\mathrm{p}(-278 /-28: 94 \mathrm{AC}), \mathrm{p}(-278 /-28: 64 \mathrm{AC})$, $\mathrm{p}(-278 /-28: 48 \mathrm{AC})$, and $\mathrm{p}(-278 /-28: 32 \mathrm{AC})$, respectively.

\subsection{Transient Transfection and Dual Luciferase Assay}

The Sf9 cells were seeded onto a 24 -well plate $\left(4 \times 10^{5}\right.$ cells/well $)$ and were then transiently co-transfected with CYP6CY3 promoter-pGL3 luciferase reporter constructs $(2 \mu \mathrm{g} /$ well) and the internal Renilla luciferase control reporter plasmid phRL-TK (Promega; $0.2 \mu \mathrm{g} /$ well) using the Cellfectin-II reagent (Invitrogen; $2 \mu \mathrm{L}$ per well). After $48 \mathrm{~h}$, the cells were harvested, and the resulting lysates were used to measure the Renilla and firefly luciferase activities on an FLx800TM fluorescence microplate reader (Biotek, Winooski, Vermont, USA). For nicotine induction, nicotine at a final concentration of $24.7 \mu \mathrm{M} / \mathrm{L}$, or an equal volume of methanol (control), was added to the wells sixteen hours post-transfection. After $24 \mathrm{~h}$ induction, the cells were harvested, and the resulting lysates were used to measure the renilla and firefly luciferase activities. The relative firefly luciferase activity normalized against the Renilla luciferase activity reported for each construct represents the mean \pm the standard error of three independent transfections. The induction folds reported are expressed as the ratio of the CYP6CY3 promoter-pGL3 relative firefly activity to the basal relative firefly activity (pGL3 control). All of the experiments were repeated three times, and each figure shows one representative experiment.

\subsection{Isolation of Cis Element Binding Proteins, Protein Identification and Bioinformatics Analysis}

The DNA fragments covering the (AC) $\mathrm{n}$ repeat region (-221 to -138) were amplified while using $\mathrm{p}(-998 /+71)$ as the template with the primer pair, PulldownF and PulldowR (Table S1). The DNA fragments were biotinylated with a Biotin $3^{\prime}$ End DNA Labeling Kit (Thermo), following the manufacturer's instructions, and the biotinylated DNA fragments were immobilized with Dynabeads ${ }^{\circledR}$ 
MyOne $^{\mathrm{TM}}$ Streptavidin T1 (Invitrogen), according to the instructions. Nuclear proteins extracted from apterous M. persicae nicotianae adults while using an EpiQuik ${ }^{\mathrm{TM}}$ Nuclear Extraction Kit II (Epigentek, Farmingdale, NY, USA) were incubated with a biotin-DNA-Dynabeads complex for $30 \mathrm{~min}$. at room temperature with gentle rotation. Next, the complexes were washed with PBS (pH 7.4) twice. Finally, the DNA binding proteins were eluted with $0.1 \%$ SDS for $8 \mathrm{~min}$. at room temperature. The protein content was determined with the Bradford (1976) [53] method using bovine serum albumin as the standard. The protein sample was lyophilized and rehydrated in $30 \mu \mathrm{L} 50 \mathrm{mM} \mathrm{NH}_{4} \mathrm{HCO}_{3}$ containing $50 \mathrm{ng}$ trypsin. After overnight digestion at $37^{\circ} \mathrm{C}$, the peptides were extracted three times with $0.1 \%$ TFA in $60 \% \mathrm{ACN}$. The extracts were pooled together and then lyophilized. The protein sample was analysed with capillary high-performance liquid chromatography-mass spectral analysis (CE/HPLC-MS) by Aptbiotech Co., Ltd. (Shanghai, China). The identified proteins were searched against the NCBI and Uniprot databases and were then combined with the results that were obtained from the aphid database (http://www.aphidbase.com/).

\subsection{Co-transfection of AhR, ARNT or CncC with CYP6CY3 Promoter-pGL3}

Sf9 cells were seeded onto a 24 -well plate $\left(4 \times 10^{5}\right.$ cells/well $)$ and were transiently co-transfected with p(-998/+71) $(1 \mu \mathrm{g} /$ well), pAC-AhR/pAC-ARNT/pAC-CncC $(1 \mu \mathrm{g} /$ well $)$ and the internal Renilla luciferase control reporter plasmid phRL-TK (Promega; $0.2 \mu \mathrm{g} /$ well) while using the Cellfectin-II reagent (Invitrogen; $2 \mu \mathrm{L}$ per well). After $48 \mathrm{~h}$, the cells were harvested, and the resulting lysates were used to measure the Renilla and firefly luciferase activities, as described above.

\subsection{Rearing on an Artificial Diet and dsRNA Feeding}

We designed specific primers using the DNAMAN 6.0 software based on the AhR, ARNT, Hsp90, Camp, CncC, CYP6CY3, and CYP6CY4 sequences (Supplementary Data S3) and the predicted possible interference sites from the online prediction software (http://www.dkfz.de/signaling/e-rnai3/). The gene fragments were amplified from cDNA and cloned into pGEM-T (Promega, USA). The purified plasmids served as templates for RNA synthesis while using the T7 RiboMAX ${ }^{\mathrm{TM}}$ Express RNAi System (Promega). ECFP dsRNA was used as the control and was synthesized under the same conditions as the primers (Table S1). The artificial diet and the rearing method that were used for this study were reported previously [23,54-56]. The diet was prepared in DEPC-treated water to ensure the absence of RNase activity. For the dsRNA feeding experiments, dsRNA was added into the artificial diet at a $100 \mathrm{ng} / \mathrm{\mu L}$ concentration. An artificial diet containing dsRNA-ECFP was used as a control. Sixty adult apterous $M$. persicae nicotianae were transferred onto the artificial diet device for rearing. To determine the effect of AhR, ARNT, Hsp90, Camp, and CncC knockdown on CYP6CY3 expression, the aphids were fed an artificial diet containing dsRNA $(100 \mathrm{ng} / \mu \mathrm{L})$ for $48 \mathrm{~h}$, and then the aphids were collected for RT-qPCR.

Sixty adult apterous aphids were transferred to the artificial diet containing nicotine $(100 \mathrm{mg} / \mathrm{L})$ mixed with dsRNA (final concentration $100 \mathrm{ng} / \mu \mathrm{L}$ ), using the dsRNA-ECFP as the control, to assess the modulation effects of the gene expression on nicotine toxicology in M. persicae nicotianae. Three replicates were performed, and mortality was assessed after $48 \mathrm{~h}$.

Supplementary Materials: Supplementary materials can be found at http://www.mdpi.com/1422-0067/20/18/ $4521 / \mathrm{s} 1$.

Author Contributions: Conceived and designed the experiments: Y.P., T.P. and Q.S. Performed the experiments: Y.P., T.P., J.S., X.Z. and F.T. Analyzed the data: T.P. and Y.P. Contributed reagents/materials/analysis tools: Q.S. Wrote the paper: T.P., Y.P., P.X. and Q.S. Bioinformatic analysis: T.P. and Q.S. All authors read and approved the final manuscript.

Funding: This work was sponsored by the National Natural Science Foundation of China (31572024, 31772188), the China Postdoctoral Science Foundation (2014M550892) and tobacco integrated pest management of China tobacco (110201603011).

Acknowledgments: The names of the P450s mentioned in this paper were based on the Blast results reported by David Nelson (Department of Molecular Science, University of Tennessee, Memphis) using the following website: http://blast.uthsc.edu/. 
Conflicts of Interest: The authors declare no competing financial interests.

$\begin{array}{ll}\text { Abbreviations } & \\ \text { P450 } & \text { cytochrome P450 monooxygenase } \\ \text { EcRE } & \text { ecdysone response element } \\ \text { ARE } & \text { antioxidant response element } \\ \text { XRE } & \text { xenobiotic response element } \\ \text { XRE-xan } & \text { xenobiotic response element to xanthotoxin } \\ \text { AhR } & \text { aryl hydrocarbon receptor } \\ \text { ARNT } & \text { aryl hydrocarbon receptor nuclear translocator } \\ \text { XRE-Fla } & \text { xenobiotic response element to flavone } \\ \text { bHLH } & \text { basic helix-loop-helix } \\ \text { CncC } & \text { cap 'n' collar/basic region leucine zipper (Cnc-bZIP) transcription factor; } \\ \text { Camp } & \text { cyclic AMP-dependent transcription factor } \\ \text { PAS (PER-ARNT-SIM) } & \text { period (Per)-ARNT-single-minded (Sim) } \\ \text { Q-rich } & \text { Glutamine-rich } \\ \text { UTR } & \text { Untranslated Regions } \\ \text { TSS } & \text { transcription start site } \\ \text { CE/HPLC-MS } & \text { capillary high-performance liquid chromatography-mass spectral analysis } \\ \text { NCBI } & \text { The National Center for Biotechnology Information } \\ \text { SRA } & \text { Sequence Read Archive } \\ \text { Hsp90 } & \text { heat shock protein 90 } \\ \text { ECFP } & \text { Enhanced cyan fluorescent protein } \\ \text { dsRNA } & \text { double-stranded RNA } \\ \text { RNAi } & \text { RNA interference } \\ \text { qRT-PCR } & \text { quantitative RT-PCR } \\ & \end{array}$

\section{References}

1. Blackman, R.L.; Eastop, V.F. Aphids on the World's Crops: An Identification and Information Guide; John Wiley \& Sons Ltd.: Chichester, UK, 2000.

2. Blackman, R.L. Morphological discrimination of a tobacco-feeding form from Myzus persicae (Sulzer) (Hemiptera: Aphididae), and a key to New world Myzus (Nectarosiphon) species. Bull. Entomol. Res. 1987, 77, 713-730. [CrossRef]

3. Margaritopoulos, J.T.; Malarky, G.; Tsitsipis, J.A.; Blackman, R.L. Microsatellite DNA and behavioural studies provide evidence of host-mediated speciation in Myzus persicae (Hemiptera: Aphididae). Biol. J. Linn. Soc. Lond. 2007, 91, 687-702. [CrossRef]

4. Cardoza, Y.J.; Wang, S.F.; Reidy-Crofts, J.; Edwards, O.R. Phloem alkaloid tolerance allows feeding on resistant Lupinus angustifolius by the aphid Myzus persicae. J. Chem. Ecol. 2006, 32, 1965-1976. [CrossRef] [PubMed]

5. Li, X.; Berenbaum, M.R.; Schuler, M.A. Molecular cloning and expression of CYP6B8: A xanthotoxin-inducible cytochrome P450 cDNA from Helicoverpa zea. Insect Biochem. Mol. Biol. 2000, 30, 75-84. [CrossRef]

6. Li, W.; Berenbaum, M.R.; Schuler, M.A. Molecular analysis of multiple CYP6B genes from polyphagous papilio species. Insect Biochem. Mol. Biol. 2001, 31, 999-1011. [CrossRef]

7. Li, X.; Berenbaum, M.R.; Schuler, M.A. Plant allelochemicals differentially regulate Helicoverpa zea cytochrome P450 genes. Insect Mol. Biol. 2002, 11, 343-352. [CrossRef] [PubMed]

8. Li, X.; Schuler, M.A.; Berenbaum, M.R. Molecular mechanisms of metabolic resistance to synthetic and natural xenobiotics. Annu. Rev. Entomol. 2007, 52, 231-253. [CrossRef]

9. Feyereisen, R. Insect CYP genes and P450 enzymes. In Insect Molecular Biology and Biochemistry; Gilbert, L.I., Ed.; Elsevier: Amsterdam, The Netherlands, 2011; pp. 236-295.

10. Schuler, M.A. P450s in plant-insect interactions. Biochim. Biophys. Acta. 2011, 1814, 36-45. [CrossRef]

11. Schuler, M.A. Insect P450s: Mounted for battle in their war against toxins. Mol. Ecol. 2012, 21, 4157-4159. [CrossRef]

12. Feyereisen, R. Insect P450 enzymes. Annu. Rev. Entomol. 1999, 44, 507-533. [CrossRef] 
13. Mao, W.; Berhow, M.A.; Zangerl, A.R.; McGovern, J.; Berenbaum, M.R. Cytochrome P450-mediated metabolism of xanthotoxin by papilio multicaudatus. J. Chem. Ecol. 2006, 32, 523-536. [CrossRef]

14. Scott, J.G. Cytochromes P450 and insecticide resistance. Insect Biochem. Mol. Biol. 1999, 29, 757-777. [CrossRef]

15. Snyder, M.J.; Glendinning, J.I. Causal connection between detoxification enzyme activity and consumption of a toxic plant compound. J. Comp. Physiol. A 1996, 179, 255-261. [CrossRef]

16. Bass, C.; Zimmer, C.T.; Riveron, J.M.; Wilding, C.S.; Wondji, C.S.; Kaussmann, M.; Field, L.M.; Williamson, M.S.; Nauen, R. Gene amplification and microsatellite polymorphism underlie a recent insect host shift. Proc. Natl. Acad. Sci. USA 2013, 110, 19460-19465. [CrossRef]

17. Ramsey, J.S.; Elzinga, D.A.; Sarkar, P.; Xin, Y.R.; Ghanim, M.; Jander, G. Adaptation to nicotine feeding in Myzus persicae. J. Chem. Ecol. 2014, 40, 869-877. [CrossRef]

18. Puinean, A.M.; Foster, S.P.; Oliphant, L.; Denholm, I.; Field, L.M.; Millar, N.S.; Williamson, M.S.; Bass, C. Amplification of a cytochrome P450 gene is associated with resistance to neonicotinoid insecticides in the aphid Myzus persicae. PLoS Genet. 2010, 6, e1000999. [CrossRef]

19. Brown, R.P.; McDonnell, C.M.; Berenbaum, M.R.; Schuler, M.A. Regulation of an insect cytochrome P450 monooxygenase gene (CYP6B1) by aryl hydrocarbon and xanthotoxin response cascades. Gene 2005, 358, 39-52. [CrossRef]

20. McDonnell, C.M.; Brown, R.P.; Berenbaum, M.R.; Schuler, M.A. Conserved regulatory elements in the promoters of two allelochemical-inducible cytochrome P450 genes differentially regulate transcription. Insect Biochem. Mol. Biol. 2004, 34, 1129-1139. [CrossRef]

21. Petersen, R.A.; Niamsup, H.; Berenbaum, M.R.; Schuler, M.A. Transcriptional response elements in the promoter of CYP6B1, an insect P450 gene regulated by plant chemicals. Biochim. Biophys. Acta. 2003, 1619, 269-282. [CrossRef]

22. Petersen Brown, R.; Berenbaum, M.R.; Schuler, M.A. Transcription of a lepidopteran cytochrome P450 promoter is modulated by multiple elements in its $5^{\prime}$ UTR and repressed by 20-hydroxyecdysone. Insect Mol. Biol. 2004, 13, 337-347. [CrossRef]

23. Peng, T.; Pan, Y.; Gao, X.; Xi, J.; Zhang, L.; Ma, K.; Wu, Q.; Zhang, J.; Shang, Q. Reduced abundance of the CYP6CY3-targeting let-7 and miR-100 miRNAs accounts for host adaptation of Myzus persicae nicotianae. Insect Biochem. Mol. Biol. 2016, 75, 89-97. [CrossRef]

24. Vandesompele, J.; De Preter, K.; Pattyn, F.; Poppe, B.; Van Roy, N.; De Paepe, A.; Speleman, F. Accurate normalization of real-time quantitative RT-PCR data by geometric averaging of multiple internal control genes. Genome Biol. 2002, 3, RESEARCH0034. [CrossRef]

25. Coumailleau, P.; Poellinger, L.; Gustafsson, J.A.; Whitelaw, M.L. Definition of a minimal domain of the dioxin receptor that is associated with Hsp90 and maintains wild type ligand binding affinity and specificity. J. Biol. Chem. 1995, 270, 25291-25300. [CrossRef]

26. Goryo, K.; Suzuki, A.; Del Carpio, C.A.; Siizaki, K.; Kuriyama, E.; Mikami, Y.; Kinoshita, K.; Yasumoto, K.; Rannug, A.; Miyamoto, A.; et al. Identification of amino acid residues in the Ah receptor involved in ligand binding. Biochem. Biophys. Res. Commun. 2007, 354, 396-402. [CrossRef]

27. Kumar, M.B.; Ramadoss, P.; Reen, R.K.; Vanden Heuvel, J.P.; Perdew, G.H. The Q-rich subdomain of the human Ah receptor transactivation domain is required for dioxin-mediated transcriptional activity. J. Biol. Chem. 2001, 276, 42302-42310. [CrossRef]

28. Pan, Y.; Yang, C.; Gao, X.; Peng, T.; Bi, R.; Xi, J.; Xin, X.; Zhu, E.; Wu, Y.; Shang, Q. Spirotetramat resistance adaption analysis of Aphis gossypii Glover by transcriptomic survey. Pestic. Biochem. Physiol. 2015, 124, 73-80. [CrossRef]

29. Mao, Y.B.; Cai, W.J.; Wang, J.W.; Hong, G.J.; Tao, X.Y.; Wang, L.J.; Huang, Y.P.; Chen, X.Y. Silencing a cotton bollworm P450 monooxygenase gene by plant-mediated RNAi impairs larval tolerance of gossypol. Nat. Biotechnol. 2007, 25, 1307-1313. [CrossRef]

30. Mao, Y.B.; Tao, X.Y.; Xue, X.Y.; Wang, L.J.; Chen, X.Y. Cotton plants expressing CYP6AE14 double-stranded RNA show enhanced resistance to bollworms. Transgenic Res. 2011, 20, 665-673. [CrossRef]

31. Lenhard, B.; Sandelin, A.; Carninci, P. Metazoan promoters: Emerging characteristics and insights into transcriptional regulation. Nat. Rev. Genet. 2012, 13, 233-245. [CrossRef]

32. Wittkopp, P.J.; Kalay, G. Cis-regulatory elements: Molecular mechanisms and evolutionary processes underlying divergence. Nat. Rev. Genet. 2012, 13, 59-69. [CrossRef] 
33. Zhang, C.; Luo, X.; Ni, X.; Zhang, Y.; Li, X. Functional characterization of cis-acting elements mediating flavone-inducible expression of CYP321A1. Insect Biochem. Mol. Biol. 2010, 40, 898-908. [CrossRef]

34. Zhang, C.; Wong, A.; Zhang, Y.; Ni, X.; Li, X. Common and unique cis-acting elements mediate xanthotoxin and flavone induction of the generalist P450 CYP321A1. Sci. Rep. 2014, 4, 6490. [CrossRef]

35. Kalsi, M.; Palli, S.R. Transcription factors, $\mathrm{CncC}$ and Maf, regulate expression of CYP6BQ genes responsible for deltamethrin resistance in Tribolium castaneum. Insect Biochem. Mol. Biol. 2015, 65, 47-56. [CrossRef]

36. Misra, J.R.; Horner, M.A.; Lam, G.; Thummel, C.S. Transcriptional regulation of xenobiotic detoxification in drosophila. Genes Dev. 2011, 25, 1796-17806. [CrossRef]

37. Gemayel, R.; Vinces, M.D.; Legendre, M.; Verstrepen, K.J. Variable tandem repeats accelerate evolution of coding and regulatory sequences. Annu. Rev. Genet. 2010, 44, 445-477. [CrossRef]

38. Vinces, M.D.; Legendre, M.; Caldara, M.; Hagihara, M.; Verstrepen, K.J. Unstable tandem repeats in promoters confer transcriptional evolvability. Science 2009, 324, 1213-1216. [CrossRef]

39. Rockman, M.V.; Wray, G.A. Abundant raw material for cis-regulatory evolution in humans. Mol. Biol. Evol. 2002, 19, 1991-2004. [CrossRef]

40. Huang, T.S.; Lee, C.C.; Chang, A.C.; Lin, S.; Chao, C.C.; Jou, Y.S.; Chu, Y.W.; Wu, C.W.; Whang-Peng, J. Shortening of microsatellite deoxy(CA) repeats involved in GL331-induced down-regulation of matrix metalloproteinase-9 gene expression. Biochem. Biophys. Res. Commun. 2003, 300, 901-907. [CrossRef]

41. Shimajiri, S.; Arima, N.; Tanimoto, A.; Murata, Y.; Hamada, T.; Wang, K.Y.; Sasaguri, Y. Shortened microsatellite $\mathrm{d}(\mathrm{CA}) 21$ sequence down-regulates promoter activity of matrix metalloproteinase 9 gene. FEBS Lett. 1999, 455, 70-74. [CrossRef]

42. Kewley, R.J.; Whitelaw, M.L.; Chapman-Smith, A. The mammalian basic helix-loop-helix/PAS family of transcriptional regulators. Int. J. Biochem. Cell Biol. 2004, 36, 189-204. [CrossRef]

43. Perdew, G.H. Association of the Ah receptor with the 90-kDa heat shock protein. J. Biol. Chem. 1988, 263, 13802-13805.

44. Beischlag, T.V.; Luis Morales, J.; Hollingshead, B.D.; Perdew, G.H. The aryl hydrocarbon receptor complex and the control of gene expression. Crit. Rev. Eukaryot. Gene Expr. 2008, 18, 207-250. [CrossRef]

45. Chan, W.K.; Yao, G.; Gu, Y.Z.; Bradfield, C.A. Cross-talk between the aryl hydrocarbon receptor and hypoxia inducible factor signaling pathways. Demonstration of competition and compensation. J. Biol. Chem. 1999, 274, 12115-12123. [CrossRef]

46. Chiaro, C.R.; Patel, R.D.; Marcus, C.B.; Perdew, G.H. Evidence for an aryl hydrocarbon receptor-mediated cytochrome p450 autoregulatory pathway. Mol. Pharmacol. 2007, 72, 1369-1379. [CrossRef]

47. Nebert, D.W.; Dalton, T.P. The role of cytochrome P450 enzymes in endogenous signalling pathways and environmental carcinogenesis. Nat. Rev. Cancer 2006, 6, 947-960. [CrossRef]

48. Nukaya, M.; Moran, S.; Bradfield, C.A. The role of the dioxin-responsive element cluster between the Cyp1a1 and Cyp1a2 loci in aryl hydrocarbon receptor biology. Proc. Natl. Acad. Sci. USA 2009, 106, 4923-4928. [CrossRef]

49. Sato, W.; Suzuki, H.; Sasaki, T.; Kumagai, T.; Sakaguchi, S.; Mizugaki, M.; Miyairi, S.; Yamazoe, Y.; Nagata, K. Construction of a system that simultaneously evaluates CYP1A1 and CYP1A2 induction in a stable human-derived cell line using a dual reporter plasmid. Drug Metab. Pharmacokinet. 2010, 25, 180-189. [CrossRef]

50. Schmidt, J.V.; Bradfield, C.A. Ah receptor signaling pathways. Annu. Rev. Cell Dev. Biol. 1996, 12, 55-89. [CrossRef]

51. Whitlock, J.P., Jr. Induction of cytochrome P4501A1. Annu. Rev. Pharmacol. Toxicol. 1999, 39, 103-125. [CrossRef]

52. Pfaffl, M.W. A new mathematical model for relative quantification in real-time RT-PCR. Nucleic Acids Res. 2001, 29, e45. [CrossRef]

53. Bradford, M.M. A rapid and sensitive method for the quantitation of microgram quantities of protein utilizing the principle of protein-dye binding. Anal. Biochem. 1976, 72, 248-254. [CrossRef]

54. Peng, T.; Pan, Y.; Gao, X.; Xi, J.; Zhang, L.; Yang, C.; Bi, R.; Yang, S.; Xin, X.; Shang, Q. Cytochrome P450 CYP6DA2 regulated by $\mathrm{CncC}$ is associated with the gossypol tolerance in Aphis gossypii Glover. Insect Mol. Biol. 2016, 25, 450-459. [CrossRef] 
55. Peng, T.; Pan, Y.; Yang, C.; Gao, X.; Xi, J.; Wu, Y.; Huang, X.; Zhu, E.; Xin, X.; Zhan, C.; et al. Over-expression of CYP6A2 is associated with spirotetramat resistance and cross-resistance in the resistant strain of Aphis gossypii Glover. Pestic. Biochem. Physiol. 2016, 126, 64-69. [CrossRef]

56. Gong, Y.; Yu, X.; Shang, Q.; Shi, X.; Gao, X. Oral delivery mediated RNA interference of a carboxylesterase gene results in reduced resistance to organophosphorus insecticides in the cotton aphid, Aphis gossypii Glover. PLOS ONE 2014, 9, e102823. [CrossRef]

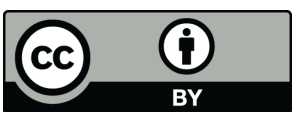

(C) 2019 by the authors. Licensee MDPI, Basel, Switzerland. This article is an open access article distributed under the terms and conditions of the Creative Commons Attribution (CC BY) license (http://creativecommons.org/licenses/by/4.0/). 